\title{
Physical examination performed by general practitioners in 5 community health service institutions in Beijing: an observational study
}

Yun Wei ${ }^{1}$, Feiyue Wang ${ }^{2}$, Zhaolu Pan ${ }^{2}$, Meirong Wang ${ }^{2}$, Guanghui Jin ${ }^{2 \dagger}$ and Xiaogin $\mathrm{Lu}^{2^{*+}+(\mathbb{0}}$

\begin{abstract}
Background: Physical examination is a core component of consultation. Little is known about the status quo of physical examinations performed by general practitioners in community health service institutions in China. The aim of this study was to investigate general practitioners' performance of physical examinations in consultations.

Methods: An observational study was conducted in 5 community health service institutions in Beijing between November 2019 and January 2020. Eleven general practitioners were observed for one workday. Information of consecutive consultations was recorded including patient characteristics, reasons for encounter, physical examinations performed by general practitioners, length of consultation time and time spent on specific activities in consultations.

Results: A total of 682 consultations of 11 general practitioners were recorded. Physical examinations were performed in 126 consultations (15.8\%). Physical examination was more likely to be performed in patients visiting with symptoms $(P<0.001)$. Majority of the 126 physical examinations were distributed in "Head, face, and neck examination" $(n=54,42.9 \%)$ and "Cardiovascular examination" $(n=55,43.7 \%)$. No physical examination was performed on skin, male genitalia, female breasts and genitalia, and neurological systems. Total $2823 \mathrm{~min}$ of activities were observed and recorded. General practitioners only spent $3.1 \%$ of the recorded time on physical examination, which was less than the time spent on taking history (18.2\%), test (4.9\%), diagnosis (22.7\%), therapy (38.4\%), and health education (8.6\%). The average time spent on physical examinations was $0.8 \pm 0.4$ min per consultation.
\end{abstract}

Conclusion: Physical examination was insufficiently performed by general practitioners in community health service institutions in Beijing. More time and commitment should be advocated for improving the quality of physical examinations in primary care.

Keywords: Physical examination, Consultation, Community health service, General practitioner, Beijing

\section{Background}

Primary care is an essential component of high-performing health care system. Due to the dilapidated primary care infrastructure and health care inequity,

\footnotetext{
*Correspondence: cumsfmxq@ccmu.edu.cn

${ }^{\dagger}$ Guanghui Jin and Xiaoqin Lu contributed equally to this work.

${ }^{2}$ Department of General Practice, School of General Practice

and Continuing Education, Capital Medical University, No. 10, Xitoutiao,

You'anmenwai, Fengtai District, Beijing 100069, China

Full list of author information is available at the end of the article
}

promoting community health service became a prioritized agenda in the health care reform of China [1]. Primary care network was re-strengthened based on the development of community health service institutions (CHSIs) in China, comprising community health centers (CHCs) and community health stations (CHSs). CHSs are small-scale clinics as satellite sites of CHCs [2]. General practitioners (GPs) are the first contact of health care in $\mathrm{CHCs}$ and CHSs delivering ambulatory care for patients with acute and chronic diseases 
in community [3]. Till 2019, there were 35,013 CHSIs across China, and the number of patient visits to CHSIs was 860 million in 2019 [4], which was over twice the number in 2009 [5].

Physical examination (PE) is a key process for medical diagnosis and a core component of consultation [6], which obtains findings via inspection, palpation, percussion, and auscultation [7]. Previous evidence indicated that obtaining a good patient history could result in correct diagnosis in $70 \%$ of cases, with a thorough physical examination, the rate would increase to $90 \%$ [8]. Performing PE in general practice not only helps to collect diagnostic information but expresses the fundamental humanity of doctor-patient relationships [9]. Doctors' patience and physical contact may relax patients and make them feel cared. It is essential for providing patient-centered care, which is a fundamental principle of general practice [10].

However, with the expansion of laboratory tests, there is a tendency for clinicians relying increasingly on laboratory reports rather than PE and clinical judgment [11-13]. It was reported in the United States that physicians spent less than $18 \%$ of their on-duty time on $\mathrm{PE}$ in patients admitted to hospital service [14]. Inadequacies of physical examination may influence patient care. As indicated in a study, almost $50 \%$ of diagnostic errors found in outpatient clinics can be traced to errors in PE [15]. The errors in most cases were that the appropriate PE maneuver has never been performed in consultations [16].

Considering the trend that clinical use of PE in hospital has decreased, there is a concern about the adequacy of GPs' performance of PE in general practice consultations [11-14]. A study in Australian general practice reported that PE was observed in $64.5 \%$ of consultations and another study in Estonia showed that PE was performed in $79.0 \%$ of consultations $[7,17]$. As the number of visits to CHSIs is increasing very fast, the performance and quality of $\mathrm{PE}$, in appropriate diagnosis and management could be undermined. However, the GPs' performance of PE was inconsistently reported in China. A study in Guangzhou reported $72.8 \%$ of consultations involved PE [18], while another study in Beijing found that PE only took place in $28.0 \%$ of consultations [19]. These studies reported the performance rate of $\mathrm{PE}$, however, detailed information of $\mathrm{PE}$ in general practice consultations has not been depicted yet in China. Thus, this study aimed to investigate detailed information of the performance of PE in general practice consultations and explore possible differences in PE across GP characteristics, to provide evidence for improving the quality of general practice consultations in China.

\section{Methods}

This was an observational study conducted in five CHSIs in Beijing, China between November 2019 to January 2020.

\section{Ethics statement}

This study was approved by the Ethical Committee of the Capital Medical University, Beijing, China. Written informed consent was obtained from each participating GP in this study. Verbal consent was obtained from patient because acquisition of written consent could potentially interfere the consultation process. All participants' information was kept confidential and tracked anonymously with identification number only.

\section{Setting and participants}

The study was conducted in five CHSIs in Beijing as a convenience sample with ensured accessibility and availability for patients and stable amounts of visits. Purposive sampling was used to recruit GPs according to the following criteria: (a) work experience in general practice for over 2 years; (b) stable amounts of visits; (c) consent to participate in this research. GPs who were seeing patients for only half a day per week and GPs who were trainees rotating in $\mathrm{CHCs} / \mathrm{CHSs}$ were excluded. Fifteen eligible GPs were invited, and eleven GPs agreed to participate in the study. All consecutive patients visiting the recruited GPs on the workday of observation were recruited with verbal consents. Patients were excluded if they visited for illness certificate or didn't register for a formal consultation.

\section{Observation form}

The observation form in this study was based on the Municipal Medical Regulations on CHSIs in Beijing and previous literatures [17-20]. Prior to the study, two GPs were observed to test and modify the observation form. The modified observation form consisted of patient characteristics (age, sex, insurance status, etc), reasons for encounter (RFEs), PEs performed by GPs, the length of consultation time and time spent on specific activities (including history taking, PE, test, diagnosis, therapy, and etc.) performed by GPs.

\section{Data collection}

Each GP was observed for one workday during November 2019 to January 2020. The observation was between the beginning and end of workday (from 8 am to $5 \mathrm{pm}$ ), excluding time spent in none-consultation activities (e.g. lunch, meeting).

Three postgraduate students (one full-time master candidate and two PhD candidates in general practice) were trained as observers in this study. A training session was 
conducted before the observation. Medical activities performed by GPs and time spent in consultations were recorded by the observer. For general examination, the observer would record the activities visibly performed in GP-patient consultations, such as temperature and lymph node examination. The activities of inspection, such as first impression, nutritional status, mental state examination (MSE), were not recorded due to the difficulty in identifying the activities by the observer. For skin examination, the observer would record the activities if the GPs made obvious inspection or asked patients to expose skin. Comprehensive PE was defined as thorough examination of multiple systems of the whole body in this study. The length of consultation was recorded with phone timer which was from the patient sitting down till the patient leaving the consultation room. Specific PE examinations and time spent on consultation activities were recorded. When multiple activities were performed at the same time, all activities were recorded in the same interval. Given that checking the notes with GPs after each consultation will potentially affect workflow, the information recorded in consultations was checked with GPs at the end of one-day observation. To avoid interrupting GPs' performance, we would explain to GPs that this research will not affect their annual performance appraisal. For each GP, there was an observer (master candidate or $\mathrm{PhD}$ candidate) seated in the least intrusive corner of consultation room who would talk to neither the GPs nor patients. Additionally, information of the participated GPs was collected, including age, sex, education, working years, professional position, and training experience.

\section{Data coding}

The RFEs were coded using the International Classification of Primary Care, second edition (ICPC-2), which is commonly used in primary care settings [21, 22]. This standardized classification is based on codes that are classified in 17 chapters representing body systems and problem areas [23].

\section{Statistical analysis}

Descriptive analyses were used to describe the characteristics of patients, GPs and medical activities. Means [with standard deviation (SD)] were used to report continuous variables, while frequencies (\%) were used to report categorical variables. Differences between groups were tested using chi-square test. A 2 -tailed $P<0.05$ was regarded as statistically significant. The minutes tallied for each activity were manually abstracted, for which summary statistics were converted to percentage of total minutes. Data management and analyses were performed using Statistical Package for Social Science (SPSS), version 22.0.

\section{Results}

\section{Characteristics of GPs}

Eleven GPs participated in this study and the mean age (with SD) was $39.4 \pm 4.3$ years. Nine GPs were female. Ten GPs had a bachelor's degree and nine GPs had over 10 years of work experience. There were six GPs with senior grade title, four GPs with intermediate grade title and one GP with junior grade title. Nine GPs had training experience in general practice, including three GPs in standardized residency training program and six GPs in on-job training program. The average number of patient visits for each GP on one workday was $62.0 \pm 13.6$ (ranged from 41 to 88 ). Three GPs saw more than 70 patients, six GPs saw 51-70 patients, and two GPs saw less than 50 patients on the observed workday (Table 1).

\section{Characteristics of Patients}

A total of 682 consultations were observed in this study. Among all the patients, $53.1 \%$ were female. The mean age (with SD) of patients was $61.9 \pm 14.4$ years. The age distribution of all patients (with 2 missing) was $2.1 \%$, $9.8 \%, 44.6 \%$ and $43.3 \%$ for those aged 25 years or less, 26 years to 45 years, 46 years to 65 years and over 65 years, respectively. Majority of the patients $(96.2 \%)$ were covered by basic medical insurance, $0.1 \%$ of the patients had business insurance, and only $2.9 \%$ of the patients had no medical insurance. There were $29.9 \%$ of patients with only one health problem, $26.0 \%$ of patients with two health problems, and $44.1 \%$ of patients with three or more health problems (Table 2).

\section{Patients' reasons for encounter}

There were 1608 RFEs (2.4 per encounter) recorded from 682 consultations. Among all the RFEs, 685 were new symptoms for encounter, 850 were prior chronic conditions, and 73 RFEs were from patients visiting for test and therapeutic consultation. The top three RFES of patients with new symptoms were "R5 cough" $(n=111$, $16.2 \%)$, "R21 throat symptoms" ( $n=89,13.0 \%)$ and "R25 sputum/sputum abnormalities" ( $n=66,9.6 \%)$. The top three health problems in chronic patients were "K86 K87 hypertension" ( $n=237,27.9 \%)$, "K74 K76 ischemic heart disease" ( $n=199,23.4 \%)$ and "T93 lipid metabolism disorder" ( $n=153,18.0 \%)$ (Table 3 ).

\section{Physical examinations provided by GPs}

Among the 682 consultations, PE occurred in 108 (15.8\%) consultations. In this study, there was statistically significant difference in PE between consultations with patients visiting with symptoms and without symptoms $(P<0.001)$. The performance of PE in consultations by GP subgroups showed no significant difference between consultations in CHCs and CHSs $(15.8 \%$ in CHCs and $15.9 \%$ in CHSs, $P>$ 
Table 1 Demographic characteristics of participated GPs $(n=11)$

\begin{tabular}{|c|c|c|}
\hline Characteristics & Frequency & Percentage (\%) \\
\hline \multicolumn{3}{|l|}{ Institution } \\
\hline $\mathrm{CHC}$ & 9 & 81.8 \\
\hline $\mathrm{CHS}$ & 2 & 18.2 \\
\hline \multicolumn{3}{|l|}{ Sex } \\
\hline Male & 2 & 18.2 \\
\hline Female & 9 & 81.8 \\
\hline \multicolumn{3}{|l|}{ Education } \\
\hline Bachelor's degree & 10 & 90.9 \\
\hline Master's degree & 1 & 9.1 \\
\hline \multicolumn{3}{|l|}{ Working years } \\
\hline$\leq 10$ & 2 & 18.2 \\
\hline$>10$ & 9 & 81.8 \\
\hline \multicolumn{3}{|l|}{ Professional title $\mathrm{e}^{\mathrm{a}}$} \\
\hline Junior grade title & 1 & 9.1 \\
\hline Middle grade title & 4 & 36.4 \\
\hline Senior grade title & 6 & 54.5 \\
\hline \multicolumn{3}{|l|}{ GP training ${ }^{b}$} \\
\hline Standardized residency training & 3 & 27.3 \\
\hline On-job training & 6 & 54.5 \\
\hline No training experience & 2 & 18.2 \\
\hline \multicolumn{3}{|c|}{ Patient volume on the observation unit } \\
\hline$\leq 50$ & 2 & 18.2 \\
\hline $51-70$ & 6 & 54.5 \\
\hline$>70$ & 3 & 27.3 \\
\hline
\end{tabular}

Abbreviation: GP general practitioner, $\mathrm{CHC}$ community health centre, CHS community health station

a In China, professional titles in medicine include junior grade, middle grade, and senior grade titles, which are based upon work experience and research achievement of health professionals

${ }^{\mathrm{b}}$ Since 2011, GPs were trained through three programs in China: (i) the standardized residency training (3-year residency training for graduates of 5 -year medical school study), (ii) on-job training (1-year training for doctors who want to register as GP), (iii) assistant GP training (2-year training for graduates of 3 -year junior medical college study). Assistant GP after training always work as a rural GP in China. Some GPs who started working in primary care institutions before 2011 have no training experience

0.05). PE was performed more frequently in consultations by female GPs (17.5\% in female GPs' consultations and 9.9\% in male GPs' consultations, $P<0.05)$. The performance of PE in consultations by GPs with different education experience $(P>0.05)$, professional positions $(P>0.05)$, working experience $(P>0.05)$, training experience $(P>0.05)$ showed no significant difference. GPs with medium amount (50-70) of patient visits was more likely to perform PE in consultations in comparison with GPs with smaller amount $(<50)$ and larger amount $(>70)$ of patient visits $(P<0.05)$ (Table 4$)$.

Total 126 examinations were recorded in 108 consultations with PE. No patient was provided with comprehensive PE. The examinations performed by GPs were
Table 2 Demographic characteristics of patients in the study ( $n$ $=682$ )

\begin{tabular}{lll}
\hline Characteristics & Frequency & Percentage (\%) \\
\hline Sex & & \\
$\quad$ Male & 320 & 46.9 \\
$\quad$ Female & 362 & 53.1 \\
Age (years) & & \\
$\quad \leq 25$ & 14 & 2.1 \\
$26-45$ & 67 & 9.8 \\
$46-65$ & 304 & 44.6 \\
$>65$ & 295 & 43.3 \\
Missing & 2 & 0.3 \\
Social medical insurance & & \\
Basic medical insurance & 656 & 96.2 \\
Business insurance & 1 & 0.1 \\
Other insurance & 5 & 0.7 \\
$\quad$ Without medical insurance & 20 & 2.9 \\
Number of health problems ${ }^{\text {a discussed }}$ & & \\
1 & 204 & 29.9 \\
2 & 177 & 26.0 \\
3 or over & 301 & 44.1 \\
\hline
\end{tabular}

Note: 'health problems here refer to GPs' diagnoses of patient's disease

mainly distributed in "Head, face, and neck examination" ( $n=54,42.9 \%)$ and "Cardiovascular examination" $(n=55,43.7 \%)$. PE was less performed in respiratory system $(n=7,5.6 \%)$, musculoskeletal system $(n=8$, $6.4 \%)$, and abdominal organs $(n=2,1.6 \%)$. No PE was observed on the skin, male genitalia, female breasts and genitalia, and neurological system. Among 126 examinations, blood pressure measurement was most frequently observed ( $n=49,38.9 \%)$, followed by pharynx inspection $(n=43,34.1 \%)$. The frequency of other PEs was less than 10 (Table 5).

A total of 2615 minutes of general practice consultations were recorded. The mean length of consultation was $3.8 \pm 3.4$ minutes (ranged from 1.0 to $37.0 \mathrm{~min}$ utes, $n=682$ ). Because simultaneous activities were recorded, a total of 2823 minutes of activities were recorded. GPs only spent $3.1 \%$ of their time on PE, which was less than the time spent on taking history (18.2\%), test (ordering tests or discussing test results with patients) (4.9\%), and health education (8.6\%). Over half of the time was spent on diagnosis (entering the diagnosis information into electronic medical record system or informing patients about the diagnosis) $(22.7 \%)$ and therapy (providing therapy strategies or prescription to patients) (38.4\%) (Fig. 1). The mean length of time spent in PE was $0.8 \pm 0.4$ minutes (ranged from 0.5 to 2.0 minutes, $n=108$ ). 
Table 3 The top 20 reasons for encounter of patients with symptoms and patients with chronic problems in descending order of frequency (classified based on the chapters in the ICPC- 2)

\begin{tabular}{|c|c|c|c|c|}
\hline Order & Symptoms & $\begin{array}{l}\text { Frequency } \\
\text { (n1=685, \%) }\end{array}$ & Health problems in chronic patients & $\begin{array}{l}\text { Frequency } \\
\text { (n2=850, } \\
\%)\end{array}$ \\
\hline 1 & R5 Cough & $111(16.2)$ & K86 K87 Hypertension & $237(27.9)$ \\
\hline 2 & R21 Throat symptom/complaint & $89(13.0)$ & K74 K76 Ischaemic heart disease & $199(23.4)$ \\
\hline 3 & R25 Sputum/phlegm abnormal & $66(9.6)$ & T93 Lipid disorder & $153(18.0)$ \\
\hline 4 & R08 Nose symptom/complaint other & $47(6.9)$ & T89 T90 Diabetes & $152(17.9)$ \\
\hline 5 & D12 Constipation & $42(6.1)$ & L95 Osteoporosis & $57(6.7)$ \\
\hline 6 & P06 Sleep disturbance & $41(6.0)$ & Y85 Benign prostatic hypertrophy & $14(1.6)$ \\
\hline 7 & R07 Sneezing/nasal congestion & $22(3.2)$ & T91 Vitamin/nutritional deficiency & $13(1.5)$ \\
\hline 8 & D01, D02, D06 Abdominal pain & $21(3.1)$ & N94 Peripheral neuritis/neuropathy & $9(1.1)$ \\
\hline 9 & F16 Eyelid symptom/complaint & $20(2.9)$ & R96 Asthma & $5(0.6)$ \\
\hline 10 & L03 Low back symptom/complaint & $19(2.8)$ & K80 Cardiac arrhythmia NOS & $4(0.5)$ \\
\hline 11 & D10 Vomiting & $18(2.6)$ & T92 Gout & $2(0.2)$ \\
\hline 12 & S06 Rash localized & $18(2.6)$ & L86 Back syndrome with radiating pain & $1(0.1)$ \\
\hline 13 & D19 Teeth/gum symptom/complaint & $17(2.5)$ & B80 Iron deficiency anaemia & $1(0.1)$ \\
\hline 14 & D08 Sneezing/nasal congestion & $12(1.8)$ & P76 Depressive disorder & $1(0.1)$ \\
\hline 15 & U02 Urinary frequency/urgency & $11(1.6)$ & K96 Haemorrhoids & $1(0.1)$ \\
\hline 16 & D03 Heartburn & $10(1.5)$ & D97 Liver disease NOS & $1(0.1)$ \\
\hline 17 & N17 Vertigo/dizziness & $10(1.5)$ & - & - \\
\hline 18 & L20 Joint symptom/complaint NOS & $9(1.3)$ & - & - \\
\hline 19 & D09 Nausea & $8(1.2)$ & - & - \\
\hline \multirow[t]{2}{*}{20} & A03 Fever & $8(1.2)$ & - & - \\
\hline & Others & $86(12.6)$ & - & - \\
\hline
\end{tabular}

Abbreviation: ICPC- 2 International Classification of Primary Care, second edition

Note: ${ }^{a}$ there were 73 reasons for encounter of patients coming for test and therapeutic consultation

\section{Discussion \\ Main findings}

In this study, we described GPs' performance of PE in general practice consultations through direct observation in Beijing. The results showed that PE occurred in only $15.8 \%$ of general practice consultations. The frequency of PEs in each system varied, and the most frequent $\mathrm{PE}$ observed was blood pressure measurement (38.9\%), followed by pharynx inspection (34.1\%), which was consistent with the RFEs of patients with new symptoms and chronic health problems. In addition, GPs only spent $3.1 \%$ of the consultation time on PE, which was less than the time spent on taking history (18.2\%), test (4.9\%), diagnosis (22.7\%), therapy (38.4\%), and health education (8.6\%).

\section{Comparisons with existing literature}

The results obtained in this study demonstrated the insufficiency of PE in general practice consultations. Although PE was a fundamental skill of GPs in disease diagnosis and health promotion, it was performed by GPs in only $15.8 \%$ consultations in this study, which was even less than the results in a previous study in Beijing in $2013(28.0 \%)$ [19]. Previous studies showed that PE was observed in $64.5 \%$ of general practice consultations in Australia ( 40 consultations by 4 primary care physicians, observed over 3 weeks) [7], 79.0\% in Estonia (405 consultations, 15 consecutive patient visits to each family doctor) [17], and $72.8 \%$ in Guangzhou, China (445 consultations, 26 consultations per GP observed in one observation unit lasting for 3-4 hours) [18]. Comparing with findings in other countries and regions, the GPs in Beijing performed PE insufficiently in this study.

A lot of factors may influence the performance of PE by GPs. First, there may not be enough time for GPs to perform a complete examination. In the present study, the average length of consultation was $3.8 \pm 3.4$ minutes. As indicated in a previous study, $5 \mathrm{~min}$ is necessary for physicians to take complete medical history and perform necessary PE [24]. In addition, GPs only spent $3.1 \%$ of their time on PE and the average time spent in PE was 0.8 minutes in this study, which was much shorter than the results in a study of Estonian family practices (2.0 minutes in PE) [17]. Comprehensive and appropriate PE for further investigation of elements about disease could 
Table 4 Frequency of physical examination in consultations by different GPs characteristics

\begin{tabular}{|c|c|c|c|c|c|}
\hline Characteristics of GPs & $\begin{array}{l}\text { Number of } \\
\text { consultations }\end{array}$ & $\begin{array}{l}\text { Consultations with PE } \\
\text { (percentage, \%) }\end{array}$ & $\begin{array}{l}\text { Consultations with no PE } \\
\text { (percentage, \%) }\end{array}$ & $x^{2}$ & $\mathbf{P}$ \\
\hline Institution & & & & 0.000 & 0.994 \\
\hline $\mathrm{CHC}$ & 518 & $82(15.8)$ & $436(84.2)$ & & \\
\hline $\mathrm{CHS}$ & 164 & $26(15.9)$ & $138(84.1)$ & & \\
\hline Sex & & & & 5.069 & 0.024 \\
\hline Male & 151 & $15(9.9)$ & $136(90.1)$ & & \\
\hline Female & 531 & $93(17.5)$ & $438(82.5)$ & & \\
\hline Education & & & & 0.363 & 0.547 \\
\hline Bachelor's degree & 628 & $101(16.1)$ & $527(83.9)$ & & \\
\hline Master's degree & 54 & $7(13.0)$ & $47(87.0)$ & & \\
\hline Working years & & & & 1.813 & 0.178 \\
\hline$\leq 10$ & 147 & $18(12.2)$ & $129(87.8)$ & & \\
\hline$>10$ & 535 & $90(16.8)$ & $445(83.2)$ & & \\
\hline Professional positions & & & & 1.233 & 0.540 \\
\hline Junior grade title & 88 & $11(12.5)$ & $77(87.5)$ & & \\
\hline Intermediate grade title & 268 & $41(15.3)$ & $227(84.7)$ & & \\
\hline Senior grade title & 326 & $56(17.2)$ & $270(82.8)$ & & \\
\hline GP training & & & & 1.055 & 0.304 \\
\hline With training experience & 490 & $82(16.7)$ & $408(83.3)$ & & \\
\hline No training experience & 192 & $26(13.5)$ & $166(86.5)$ & & \\
\hline Patient visits & & & & 9.112 & 0.011 \\
\hline$\leq 50$ & 87 & $8(9.2)$ & $79(90.8)$ & & \\
\hline $51-70$ & 360 & 71 (19.7) & $289(80.3)$ & & \\
\hline$>70$ & 235 & $29(12.3)$ & $206(87.7)$ & & \\
\hline Total & 682 & $108(15.8)$ & $574(84.2)$ & - & - \\
\hline
\end{tabular}

Abbreviation: GP general practitioner, $P E$ physical examination, $C H C$ community health center, $C H S$ community health station

lead to preventive care and health promotion counseling and would create opportunities for early diagnosis [25], in which sufficient time was undoubtedly necessary. Second, the reason of patient encounters may play an important role in the performance of PE. PE was more likely to be performed in patients with symptoms $(P<0.001)$. In Beijing, the patients with chronic diseases are usually managed in CHSIs, and medication refill on a monthly basis is accessible for chronic patients [26, 27]. In this study, most encounters in general practice clinics were chronic patients visiting for regular medication refill. PE was not necessarily needed for diagnosis, as information about disease is already in the electronic medical record system and most of the chronic patients were stable. Therefore, the GPs might consider it is not necessary to perform PEs for patients. Third, it cannot be ruled out that the clinical skills and professional competence of GPs in primary care still need to be improved [28]. In a survey covering 17 provinces in China, poor capacity and skills of the GPs were found to be the most common reasons for why patients bypassed primary care institutions when they needed clinical care (32\%) [29].
In this study, the performance of PE in each system varied, with blood pressure measurement accounting for the most, followed by pharynx inspection. Blood pressure measurement is a standard procedure for GP in the follow-up of patients with chronic disease. However, the performance rate of blood pressure measurement is lower than that in a study from the US, in which all the patients (100.0\%) received blood pressure measurement at their visits [30]. The finding of high frequency of pharynx inspection was similar with a study in Turkey, in which mouth and pharynx inspection occurred most frequently in general practice clinics [24]. In this study, the most common symptoms of patients were from respiratory system, including "R5 cough", "R21 throat symptoms", and "R25 sputum/sputum abnormalities", which may be the cause of high frequency of pharynx inspection. Focused examination based on specific symptoms was most frequently performed, omitting those parts of examination believed to be low yield. However, previous evidence suggested the possibility that a simple way of strengthening the therapeutic alliance is to perform a few additional components of the PE at every visit, even 
Table 5 Frequency of physical examinations in 108 patient consultations ( $n=126)$

\begin{tabular}{|c|c|c|c|}
\hline Components of PE & $\begin{array}{l}\text { Frequency of PEs for patients } \\
\text { coming with symptoms }\end{array}$ & $\begin{array}{l}\text { Frequency of PEs for patients } \\
\text { coming with chronic patients }\end{array}$ & Total (frequency, \%) \\
\hline \multicolumn{4}{|l|}{ General examination } \\
\hline Temperature examination & 0 & 0 & $0(0.0)$ \\
\hline Lymph node examination & 0 & 0 & $0(0.0)$ \\
\hline Skin examination & 0 & 0 & $0(0.0)$ \\
\hline \multicolumn{4}{|l|}{ Head, face, and neck examination } \\
\hline Head and face inspection & 1 & 0 & $1(0.8)$ \\
\hline Corneal and conjunctival examination & 3 & 0 & $3(2.4)$ \\
\hline Pupillary light responses & 1 & 0 & $1(0.8)$ \\
\hline Visual fields & 1 & 0 & $1(0.8)$ \\
\hline Ophthalmoscopic examination & 1 & 0 & $1(0.8)$ \\
\hline Mouth inspection & 3 & 0 & $3(2.4)$ \\
\hline Pharynx inspection & 43 & 0 & $43(34.1)$ \\
\hline Thyroid palpation & 1 & 0 & $1(0.8)$ \\
\hline \multicolumn{4}{|l|}{ Cardiovascular examination } \\
\hline Blood pressure measurement & 16 & 31 & $49(38.9)^{\mathrm{a}}$ \\
\hline Pulse rate & 0 & 1 & $1(0.8)$ \\
\hline Heart sounds oscultation & 5 & 0 & $5(4.0)$ \\
\hline \multicolumn{4}{|l|}{ Respiratory examination } \\
\hline Anterior chest percussion & 2 & 0 & $2(1.6)$ \\
\hline Breath sounds oscultation of anterior chest & 5 & 0 & $5(4.0)$ \\
\hline \multicolumn{4}{|l|}{ Abdominal examination } \\
\hline Abdominal inspection & 2 & 0 & $2(1.6)$ \\
\hline Abdominal palpation & 0 & 0 & $0(0.0)$ \\
\hline Abdominal percussion & 0 & 0 & $0(0.0)$ \\
\hline Auscultation of the abdomen & 0 & 0 & $0(0.0)$ \\
\hline \multicolumn{4}{|l|}{ Musculoskeletal examination } \\
\hline Lumbar percussion & 1 & 0 & $1(0.8)$ \\
\hline Spine percussion & 2 & 0 & $2(1.6)$ \\
\hline Inspection of hands & 3 & 0 & $3(2.4)$ \\
\hline Inspection of lower limbs & 2 & 0 & $2(1.6)$ \\
\hline Male genitalia examination & 0 & 0 & $0(0.0)$ \\
\hline Female breasts and genitalia examination & 0 & 0 & $0(0.0)$ \\
\hline Neurological examination & 0 & 0 & $0(0.0)$ \\
\hline Total & 92 & 32 & $126(100.0)^{\mathrm{a}}$ \\
\hline
\end{tabular}

Abbreviation: PE physical examination

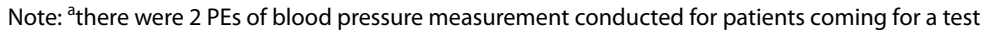

in the absence of relevant symptoms, which may improve doctor-patient relationship [30].

In addition to the frequency of PEs performed by GPs, the extent of the inadequacies of the GPs in performing detailed items of the PE is worth-noticing. For patients visiting with symptoms, such as fever, localized rash, and abdominal pain, there was no examination of temperature, skin (asking patients to expose the skin and give an examination), and abdomen (palpation, percussion, auscultation of the abdomen) performed by GPs. Besides, although there were many patients visiting with symptoms in respiratory system (e.g. cough, sputum/ phlegm abnormal), PE such as percussion and auscultation of the lungs were insufficiently performed by GPs. Oversight in PE could lead to missed or delayed diagnosis, which may be remedied if physicians paid more attention to PE in consultations [16].

Even for patients with chronic diseases, PE is very important for detecting complications. For instance, an analysis of SOLVD (Studies of Left Ventricular Dysfunction) showed that jugular venous distention (JVD) and a third heart sound (S3) were independently associated 


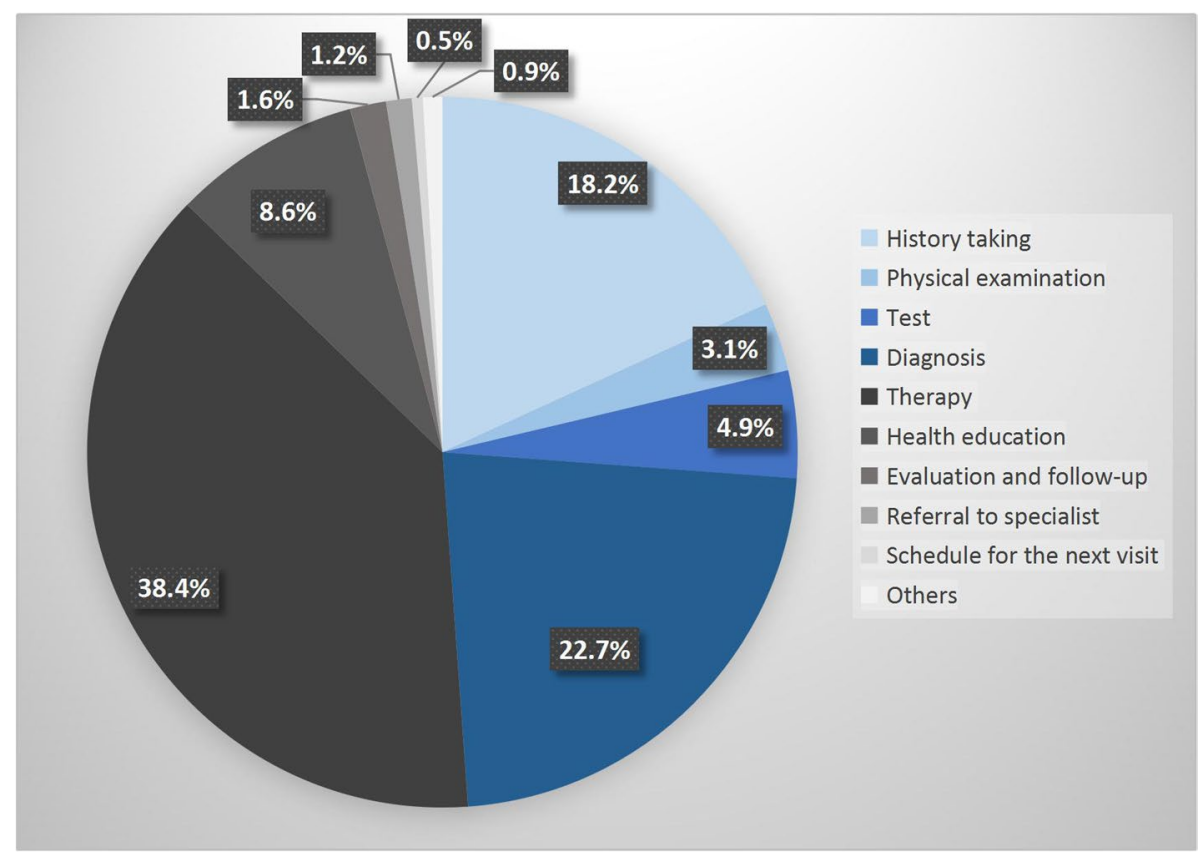

Fig. 1 Time distribution of general practitioners' activities in general practice consultations ( $n=2823$ minutes)

with progression of heart failure [31]. Patients with diabetes, several diabetic foot risk factors (neuropathy, foot deformity, minor trauma, previous ulceration or amputation) should be evaluated for lower extremity examination [32]. In this study, although most patients with hypertension, ischaemic heart disease, and diabetes were managed in CHSIs, the performance of PEs related to blood pressure, heart auscultation, and foot inspection and palpation was insufficient. PE is not only essential for diagnosis [8, 16, 33], but also critical in chronic disease management. Regular PE is one of the easiest, cheapest and most effective measure to prevent the complications of chronic diseases [34]. Therefore, more attention should be paid to PE for chronic patients in general practice.

\section{Strengths and limitations}

Overall, the present study looked into the depth of PE performed in general practice consultations in Beijing. The results showed that PE was insufficiently performed by GPs in Beijing in terms of frequency and time. This may provide evidence for improving the quality of general practice consultations in CHSIs. In addition, the method itself is a strength, as the researchers were observing rather than relying on self-report.

Our study also has limitations. First, the generalizability of the findings is limited. For example, PE was less frequently performed by GPs with fewer patients $(\leq 50$ visits) than GPs with more patient visits in this study. This result may be inconsistent with a previous study
[24], as fewer patient visits may lead to more time and chance for a PE. There were only 11 GPs recruited out of 29 GPs in 5 CHSIs in this study and only 2 GPs saw $\leq 50$ patients, data trends may not be inferred. Besides, as indicated before, except for time constraint, RFEs also influence the performance of PE. And it is possible that the performance of PE varied in GPs with different work conditions and motivation. This is a preliminary study in exploration of GPs' performance of PE, investigations in larger sample and analysis of influencing factors of PE are necessary in further researches. Second, the observer sitting in the consultation room may affect the GPs' performance. GPs may behave better than usual when under observation. Therefore, we explained to the GP before the observation that this research would not affect their annual performance appraisal. During the observation, the observers were seated in the least intrusive corner of the consultation room to avoid disturbance. Third, observations might be influenced by observer bias and recording errors could be a possible limitation in data collection. We developed a structured observation form and modified it through a pilot study. We also provided careful training for observers about the principles of observation and information recording to ensure the consistency of observation. Finally, in this observational study, some activities for general examination (especially inspection, such as first impression, nutritional status, MSE) were not recorded due to the difficulty in identifying the 
examinations by observers. Therefore, the frequency of PEs performed by GPs might be underestimated.

\section{Implications for research and practice}

This was a preliminary study showing the GPs' performance of PE in GP-patient consultations, which can be used as a basis and reference for further research exploring the influencing factors and improvement strategies of PE performance in primary care. In addition, this study also provided feedback to GPs that there should be more focus on PE in GP-patient consultations. Moreover, it also provided an opportunity of future continuing medical education to improve the quality of medical services in primary care.

\section{Conclusion}

PE was insufficiently performed by GPs in CHSIs in Beijing. More time and commitment should be advocated for appropriate PEs in primary care. Further researches may concentrate on exploration of the influencing factors of GPs' performance of PE and improvement strategies of PE performance.

\section{Abbreviations}

PE: Physical examination; GPs: General Practitioners; CHSI: Community health service institution; $\mathrm{CHC}$ : Community health centre; CHS: Community health station; RFEs: Reasons for encounter; ICPC-2: International Classification of Primary Care second edition; SD: Standard deviation; SPSS: Statistical Package for Social Science; JVD: Jugular venous distention; S3: Third heart sound.

\section{Supplementary Information}

The online version contains supplementary material available at https://doi. org/10.1186/s12875-021-01619-1.

\section{Additional file 1.}

\section{Acknowledgements}

The authors thank the Capital General Practice Research Project (17QK06) for the support. The authors also thank all of the participants for their support and help to our research.

\section{Authors' contributions}

WY, JGH, and LXQ designed the study. LXQ obtained funding and ethical approval. WY collected and analyzed the data. WFY, PZL and WMR were involved in data collection. WY drafted the manuscript. JGH and LXQ contributed to the interpretation of the results and critical revision of the manuscript for important intellectual content and approved the final version of the manuscript. All authors have read and approved the final manuscript.

\section{Funding}

This work was supported by the Capital General Practice Research Project (17QK06). The funding organization had no role in the design, conduct, analysis and interpretation or preparation of this study.

\section{Availability of data and materials}

The datasets used and/or analyzed during the current study are available from the corresponding author on reasonable request.

\section{Declarations}

Ethics approval and consent to participate

It was approved by the Ethical Committee of Capital Medical University, Beijing, China. Participants were thoroughly informed in advance about the aim of the study, orally (patients) and in writing (GPs).

\section{Consent for publication}

Not applicable.

\section{Competing interests}

The authors declare that they have no competing interests.

\section{Author details}

${ }^{1}$ Department of General Practice, Beijing Tongren Hospital, Capital Medical University, Beijing, China. ${ }^{2}$ Department of General Practice, School of General Practice and Continuing Education, Capital Medical University, No. 10, Xitoutiao, You'anmenwai, Fengtai District, Beijing 100069, China.

Received: 22 December 2020 Accepted: 22 December 2021 Published online: 14 January 2022

\section{References}

1. Wang HH, Wang JJ, Wong SY, Wong MC, Mercer SW, Griffiths SM. The development of urban community health centres for strengthening primary care in China: a systematic literature review. Br Med Bull. 2015;116:139-53. https://doi.org/10.1093/bmb/ldv043.

2. Li X, Lu J, Hu S, Cheng KK, De Maeseneer J, Meng Q, et al. The primary health-care system in China. Lancet. 2017;390(10112):2584-94. https:// doi.org/10.1016/S0140-6736(17)33109-4.

3. The State Council. Guiding Opinions of the State Council on the Development of Community Health Services [ in Chinese]. 2006 http://www.gov.cn/ zhengce/content/2008-03/28/content_6229.htm. Accessed 25 June 2021

4. National Health Commission of the People's Republic of China. Statistical Communique on the Development of Health and Family Planning in China in 2019 [in Chinese]. 2020. http://www.nhc.gov.cn/guihuaxxs/ s10748/202006/ebfe31f24cc145b198dd730603ec4442.shtm. Accessed 28 Sept 2020

5. Ministry of Health. Statistical Communique on the Development of Health in China in 2009 [in Chinese]. 2010. http://www.gov.cn/gzdt/201004/09/content_1576944.htm. Accessed 28 Sept 2020.

6. Grune S. Anamnesis and clinical examination. Dtsch Med Wochenschr. 2016;141(1):24-7.

7. Kocaballi AB, Coiera E, Tong HL, White SJ, Quiroz JC, Rezazadegan F, et al. A network model of activities in primary care consultations. J Am Med Inform Assoc. 2019;26(10):1074-82. https://doi.org/10.1093/jamia/ocz046.

8. Coulehan JL, Block MR. The medical interview. Introduction: the poor historian, third edition. Philadelphia: Davis Company; 1997. p. xix.

9. Kelly MA, Freeman LK, Dornan T. Family Physicians'Experiences of Physical Examination. Ann Fam Med. 2019;17(4):304-10. https://doi.org/10.1370/ afm.2420.

10. European Academy of Teachers in General Practice (Network within WONCA Europe). The European Definition of General Practice/Family Medicine. 2005. http://www.woncaeurope.org/sites/default/files/docum ents/Definition\%20EURACTshort\%20version.pdf. Accessed 8 Sept 2020

11. Jauhar S. The demise of the physical exam. N Engl J Med. 2006:354(6):548-51. https://doi.org/10.1056/NEJMp068013.

12. Ende J, Fosnocht KM. Clinical examination: still a tool for our times? Trans Am Clin Climatol Assoc. 2002:113:137-50.

13. Feddock CA. The lost art of clinical skills. Am J Med. 2007;120:374-8. https://doi.org/10.1016/j.amjmed.2007.01.023.

14. O'Leary KJ, Liebovitz DM, Baker DW. How hospitalists spend their time: insights on efficiency and safety. J Hosp Med. 2006;1(2):88-93. https:// doi.org/10.1002/jhm.88.

15. Singh $\mathrm{H}$, Giardina TD, Meyer AN, et al. Types and origins of diagnostic errors in primary care settings. JAMA Intern Med. 2013;173:418-25. https://doi.org/10.1001/jamainternmed.2013.2777. 
16. Verghese A, Charlton B, Kassirer JP, Ramsey M, loannidis JP. Inadequacies of Physical Examination as a Cause of Medical Errors and Adverse Events: A Collection of Vignettes. Am J Med. 2015;128(12):1322-4.e3. https://doi. org/10.1016/j.amjmed.2015.06.004.

17. Tähepold H, Maaroos HI, Kalda R, van den Brink-Muinen A. Structure and duration of consultations in Estonian family practice. Scand J Prim Health Care. 2003;21(3):167-70. https://doi.org/10.1080/02813430310000708.

18. Zhong C, Luo Z, Liang C, Zhou M, Kuang L. An overview of general practitioner consultations in China: a direct observational study. Fam Pract. 2020;37(5):682-8. https://doi.org/10.1093/fampra/cmaa039.

19. Jin G, Zhao Y, Chen C, Wang W, Du J, Lu X. The length and content of general practice consultation in two urban districts of Beijing: a preliminary observation study. PLoS One. 2015;10(8):e0135121. https://doi.org/10. 1371/journal.pone.0135121.

20. Beijing Municipal Health Commission. Opinions on Accelerating the Development of Community Health Services (in Chinese). 2000. http:// wjw.beijing.gov.cn/ Accessed 8 Sept 2020.

21. Kaneko M, Van Boven K, Takayanagi H, Kusaba T, Yamada T, Matsushima M. Multicentre descriptive cross-sectional study of Japanese home visit patients: reasons for encounter, health problems and multimorbidity. Fam Pract. 2020;37(2):227-33. https://doi.org/10.1093/fampra/cmz056.

22. Meynard A, Broers B, Lefebvre D, Narring F, Haller DM. Reasons for encounter in young people consulting a family doctor in the French speaking part of Switzerland: a cross sectional study. BMC Fam Pract. 2015;16:159. https://doi.org/10.1186/s12875-015-0375-x.

23. Classification Committee of the World Organization of Family Doctors. ICPC-2: International Classification of Primary Care. 2nd ed. Oxford: Oxford University Press; 1998

24. Güldal D, Ulusel B, Ozçakar N, Yeniçeri N, Dontlu C. The challenge of clinical interviewing and physical examination performance for general practitioners in Turkey. Fam Med. 2005;37(5):354-9.

25. Fried LP. Health promotion and disease prevention in the care of older adults: preventive practice in primary care. Md Med J. 1989 Feb;38(2):121-3.

26. Beijing Municipal Health Commission. Measures to improve medical services in primary care institutions. 2019. http://wjw.beijing.gov.cn/zwgk_ 20040/ztzl/ffzl/201912/t20191217_1244319.html. Accessed 8 Sept 2020

27. The People's Government of Beijing Municipality. Implementation plan comprehensive reforms of clinic-pharmacy separation. 2017. http://www. beijing.gov.cn/zhengce/zhengcefagui/201905/t20190522_60088.html. Accessed 8 Sept 2020.

28. Ding ZL, Fang JX, Zhao Q, Huang M. Final assessment on clinical skills in standardized training for general practitioners based on objective structured clinical examination and its analysis [in Chinese]. Chin Gen Pract. 2015;18(13):1552-1554,1559. https://doi.org/10.3969/j.issn.1007-9572. 2015.13.018.

29. Qin J, Lin C, Zhang L, Zhang Y. Patient satisfaction with primary care in highly focused districts/counties during the comprehensive reform of primary care system in China [in Chinese]. Chin Gen Pract. 2018;21:36-40.

30. Duan L, Mukherjee EM, Federman DG. The physical examination: a survey of patient preferences and expectations during primary care visits. Postgrad Med. 2020;132(1):102-8. https://doi.org/10.1080/00325481.2020 1713618.

31. Drazner MH, Rame JE, Stevenson LW, Dries DL. Prognostic importance of elevated jugular venous pressure and a third heart sound in patients with heart failure. N Engl J Med. 2001;345(8):574-81. https://doi.org/10.1056/ NEJMoa010641.

32. Johnson R, Osbourne A, Rispoli J, Verdin C. The Diabetic Foot Assessment. Orthop Nurs. 2018;37(1):13-21. https://doi.org/10.1097/NOR.0000000000 000414.

33. Asif T, Mohiuddin A, Hasan B, Pauly RR. Importance of Thorough Physical Examination: A Lost Art. Cureus. 2017;9(5):e1212. https://doi.org/10.7759/ cureus.1212.

34. Lu Y, Huang C. Importance of history taking, physical examination, and standardized treatment to chronic diseases management [in Chinese]. Chin Gen Pract. 2011:2:38-40.

\section{Publisher's Note}

Springer Nature remains neutral with regard to jurisdictional claims in published maps and institutional affiliations.

Ready to submit your research? Choose BMC and benefit from:

- fast, convenient online submission

- thorough peer review by experienced researchers in your field

- rapid publication on acceptance

- support for research data, including large and complex data types

- gold Open Access which fosters wider collaboration and increased citations

- maximum visibility for your research: over $100 \mathrm{M}$ website views per year

At BMC, research is always in progress.

Learn more biomedcentral.com/submissions 